\title{
Forest, Agriculture, and Environmental Protection as Path to Sustainable Development
}

\author{
Mauro Viccaro $\mathbb{\Phi}^{1,3}$ and Donatella Caniani ${ }^{2}$
}

\begin{abstract}
The case for the conservation of nature should not rest only with the development goals. It is part of our moral obligation to other living beings and future generations (WCED 1987, p. 57)
\end{abstract}

Sustainable development is still the main goal in international and national agendas, since its first publication in the Brundtland Report "Our Common Future" (WCED 1987). It is based on two primary concepts, which represent non-negotiable fundamental principles (Daly 2007; Holden et al. 2014): (1) the safeguarding of long-term ecological sustainability and basic human needs and (2) the promotion of intra- and inter-generational equity. Although there is no hierarchy between these concepts, ecological sustainability represents the key principle. Indeed, "development is not sustainable if it is not ecologically sustainable" (Holden et al. 2014), as highlighted by the Norwegian philosopher Arne Næss. In fact, it would be possible to satisfy basic human needs only if natural systems (air, water, soil, and biodiversity) supported human life on earth.

Ecosystems provide multiple goods and services essential for people worldwide. Ecosystem services (ES) include (MEA 2005): provisioning services such as food, water, fiber, and fuel; regulating services that affect climate, floods, disease, waste, and water

\footnotetext{
${ }^{1}$ School of Agricultural, Forests, Food and Environmental Sciences, University of Basilicata, Viale dell'Ateneo Lucano n. 10, 85100, Potenza, Italy.

${ }^{2}$ Engineering School, University of Basilicata, Viale dell'Ateneo Lucano n. 10, 85100, Potenza, Italy.

${ }^{3}$ To whom correspondence should be addressed; e-mail: mauro.viccaro@unibas.it
}

quality; cultural services that provide recreational, aesthetic, and spiritual benefits; and supporting services such as soil formation, photosynthesis, and nutrient cycling. Each ecosystem, from relatively undisturbed to semi-natural ones, offers a wide range of ES, which are all essential in meeting human needs.

Forests, representing $31 \%$ of the world's land area, host more than $80 \%$ of all living species on Earth, ensuring the livelihood of around 1.6 billion people, including 70 million natives. However, natural forest area decreases at about 6.5 million hectares every year, mainly due to conversion of tropical forests into agricultural land (FAO 2016). In 2015, the United Nations General Assembly set 17 Sustainable Development Goals (SDGs) representing a unified vision for making progress on social, economic, and environmental concerns by 2030 (United Nations 2015). Among these goals, the SDG 15 specifically referred to forests with the aim to "...ensure the conservation, restoration and sustainable use of terrestrial and inland freshwater ecosystems and their services, in particular forests..." (SDG 15.1) and "...promote the implementation of sustainable management of all types of forests, halt deforestation, restore degraded forests and substantially increase afforestation and reforestation globally" (SDG 15.2). These actions are not intended solely to preserve forests as an ecosystem but also their connected ES in order to meet different SDGs. Well-managed forests, due to the ES they provide, have a positive impact on biodiversity (SDG 15-Life on land). They can also create income (SDG $1-$ No poverty), capture and store carbon (SDG 13-Climate action), and provide food (SDG 2-Zero hunger), freshwater (SDG 6-Clean 
water and sanitation), and medical plants (SDG 3-Good health and well-being for people). However, because some services may be in conflict with each other (e.g., wood production versus biodiversity protection), sustainable forest management is necessary to find the right trade-off among the different forest ES.

Different considerations should be taken about agriculture, which covers approximately $38 \%$ of the global land surface area and is the largest terrestrial biome that does not need to be protected, such as forests, but valorized. As a semi-natural ecosystem, agriculture lies somewhere in the middle of a human-impact continuum between unmanaged natural ecosystems (e.g., tropical forests) and human domination (e.g., urban areas), providing at the same time services and disservices (Swinton et al. 2007). To meet human demand for food, fiber, and fuel, from tropical smallholder farms to big farms in North America and Europe, agriculture has generated a huge impact on Earth, becoming an important driver of global climate change, because of land-use change and greenhouse gas emissions (Smith and Sullivan 2014). Land-use change associated with agricultural development is responsible for tropical deforestation and biodiversity loss, freshwater depletion, losses of soil quality through erosion and salinization, and the increase in infectious diseases (Foley et al. 2005). It is also the primary driver for the disruption of nitrogen and phosphorus cycles and the eutrophication of water bodies.

Nevertheless, agriculture represents a key sector for fighting hunger (SDG 2) and poverty (SDG 1) as well as the main source of income for about three quarters of the poor people living in rural areas (Kanter et al. 2018). Therefore, it is necessary to adopt an ecosystem approach in agriculture (DeClerck et al. 2016) in order to strengthen its multi-functional role in providing provisioning, regulating, and cultural services. A sustainable agricultural management (Vastola et al. 2017; Viccaro et al. 2019) allows us to provide healthy food (SDG 2 and SDG 3) and fuel (SDG 7). At the same time, it also allows us to improve agricultural ecosystem services such as soil carbon sequestration (SDG 13), water storage (SDG 6), safeguarding of biodiversity (SDG 15), improved security from natural hazard and disease (SDG 3), and climate change mitigation (SDG 13). Moreover, sustainable agricultural management is important to preserve cultural services, such as rural landscapes and cultural heritage, which need to be safeguarded for future generations.
With global population projected to become about 10 billion in 2050, the pressure on natural resources will increase more and more. It is necessary to develop tools for understanding natural and human dynamics in order to manage natural resources correctly, both in agriculture and in forest, if we want to achieve a sustainable development.

This Special Issue of Natural Resources Research is a collection of nine papers, which represent different fields of knowledge concerning forest and agricultural sustainable management, particularly focusing on sustainable forest management, wildlife, land-use change, pollution, management and reuse of waste and wastewater.

In the context of sustainable forest management, Sacchelli and Bernetti (2019) developed and described a tool for defining the best forest management strategies in order to maximize the provision of forest ecosystem services. This tool, which was applied to a coniferous stand in Tuscany (central Italy), is based on a multi-objective optimization model. By exploring and depicting feasible management strategies in terms of distance from the "best solution" or "ideal point," this tool allows to identify the best strategy in providing timber production, carbon sequestration, biodiversity maintenance, and touristic-recreational function at the same time. The authors showed how it is possible to achieve a different degree of trade-off among forest ES based on the applied management strategy, and discussed the strengths and weaknesses of the tool as well as its potential future improvement.

Among the various problems occurring at the forest-agriculture interface, Cozzi et al. (2019) focused their attention on the impact of wildlife on agriculture. Given the strong conflicts among biodiversity safeguarding (SDG 15), food production (SDG 2), and income generation (SDG 1), wildlifeagriculture interactions could become serious problems in many rural areas. Therefore, starting from the factors affecting crop damages from wild boar, the authors proposed a spatial model for identifying high-risk areas of damage in order to implement mitigation actions to avoid the high costs of compensation.

Fragmentation and reduction of forests and other natural areas are surely the main causes of the human-wildlife conflicts. Understanding the change dynamics of land use and land cover (LULC) is an important issue in land sustainable management in order to ensure a sustainable, benign, and healthy environment. Three papers in this Special Issue of 
Natural Resources Research focus on this matter. Prasad and Ramesh (2019), Peng and Zhou (2019), and Statuto et al. (2019a) proposed three different GIS models for the analysis of the spatiotemporal evolution of LULC changes in an ecologically fragile area in the Alappuzha District (India), in a rural landscape in Mianzhu (China), and in a rural landscape in Basilicata region (Italy), respectively. The results are very different, highlighting the importance of the development and application of local-scale models. While in rural areas with lower population growth the landscape has naturally evolved without any human intervention (Statuto et al. 2019a), the population growth in India and China is leading to an increase in built-up land area with reduction in cultivated agricultural land (Prasad and Ramesh 2019; Peng and Zhou 2019). The authors highlighted the importance of these models for land planning to analyze land-use change dynamics in order to avoid future conflicts among alternative land uses.

Land is not the only limited natural resource used in agriculture. Indeed, modern agriculture relies heavily on mineral fertilizers, such as phosphorus. This is an essential plant nutrient but a non-renewable resource, which is expected to become scarce and depleted in the future, leading to growing concerns about the sustainability of modern agriculture. Concerning this problem, Caniani et al. (2019) evaluated the possibility to recycle phosphorus from manure and wastewater in Italy. Comparing their findings with the phosphorus demand of agricultural sector on a national and regional scale, the authors showed the potential of animal manure and civil/industrial waste as a phosphorus source for the agricultural sector.

The use of fertilizers also creates other environmental problems, such as soil and water pollution, representing a high social cost. The European Union encourages the implementation of environmentally friendly practices based on organic and integrated farming by providing financial aid. To identify the subjects of this aid, Riccioli et al. (2019) proposed a spatial multi-criteria analysis for classifying farms according to a multi-dimensional index called NIV (nitrate impact value). The NIV represents an important parameter for selecting farms to be financed in order to obtain a more efficient distribution of contributions aimed at reducing environmental impact related to agricultural activities.

The last two papers focus their attention on agricultural co-products, by-products, and waste and on the way that they can be used in the context of circular economy and environmental protection. Statuto et al. (2019b) evaluated the current potential of using different kinds of agro-forestry biomass (e.g., forest residues, cereal straw, livestock manure) as well as municipal organic waste to produce renewable energy at a regional scale (Basilicata region, Italy). Grippo et al. (2019) presented a multicriteria approach to evaluate different projects of bran use for the production of paper, biogas, and feed in southern Italy. According to the concept of circular economy, both papers showed that agricultural co-products, by-products, and waste could represent an important source for energy production and income generation, reducing the environmental impact of waste.

The papers in this special issue focused, through different analyses and models, their attention on different problems related to the sustainable management of forests and agriculture. However, they do not represent the final answer to these problems, but they provide an "incentive" to continue and improve studies related to the sustainable use of natural resources to make forests and agriculture the actual path for sustainable development.

\section{ACKNOWLEDGEMENTS}

We thank Editor-in-Chief Emmanuel John M. Carranza for accepting to publish this collection of papers in a special issue of Natural Resources Research. We are grateful to all the authors for their contributions. We acknowledge the technical assistance of the journal editorial office, Rajeswari Sundaram. We deeply appreciate the support of all the reviewers (Cristian Accastello, Andrea Amici, D.M. Arias, S. Bandyopadhyay, Earl Bardsley, Sergio Castellano, Giuseppe Cillis, Mario Cozzi, Dominika Dabrowska, Claudio Fagarazzi, Robert Feick, Jitka Fialovà, Gianluca Grilli, Istrate Irina, Ramesh Kumar, Francisco Mesìas, Gabriele Nolè, Alessandro Paletto, George Papadakis, Nicola Puletti, Mohammad Rahman, S.A. Rahaman, Francesco Riccioli, Benedetto Rocchi, Severino Romano, Sandro Sacchelli, and Adriano Sofo) for the time and effort they spent unselfishly on reviewing the manuscripts submitted to this special issue. 


\section{REFERENCES}

Caniani, D., Viccaro, M., Schiavone, C., Ponte, M. C. L., Masi, S., Mancini, I. M., et al. (2019). The balance between capturing phosphorus from manure and wastewater and the demand for crop fertilizer in Italy. Natural Resources Research. https:// doi.org/10.1007/s11053-018-9426-z.

Cozzi, M., Prete, C., Viccaro, M., \& Romano, S. (2019). Impacts of wildlife on agriculture: A spatial-based analysis and economic assessment for reducing damage. Natural Resources Research. https://doi.org/10.1007/s11053-019-09469-6.

Daly, H. E. (2007). Ecological economics and sustainable development. Cheltenham: Edward Elgar Publishing.

DeClerck, F. A., Jones, S. K., Attwood, S., Bossio, D., Girvetz, E., Chaplin-Kramer, B., et al. (2016). Agricultural ecosystems and their services: The vanguard of sustainability? Current Opinion in Environmental Sustainability, 23, 92-99.

FAO. (2016). Global forest resources assessment 2015: How are the world's forests changing?. Rome: Food and Agriculture Organization of the United Nations (FAO).

Foley, J. A., DeFries, R., Asner, G. P., Barford, C., Bonan, G., Carpenter, S. R., et al. (2005). Global consequences of land use. Science, 309(5734), 570-574.

Grippo, V., Romano, S., \& Vastola, A. (2019). Multi-criteria evaluation of bran use to promote circularity in the cereal production chain. Natural Resources Research. https://doi.org/ 10.1007/s11053-019-09457-w.

Holden, E., Linnerud, K., \& Banister, D. (2014). Sustainable development: Our common future revisited. Global Environmental Change, 26, 130-139.

Kanter, D. R., Musumba, M., Wood, S. L., Palm, C., Antle, J., Balvanera, P., et al. (2018). Evaluating agricultural trade-offs in the age of sustainable development. Agricultural Systems, $163,73-88$

MEA. (2005). Ecosystems and human well-being (Vol. 5). Washington, DC: Island Press.

Peng, W., \& Zhou, J. (2019). Development of land resources in transitional zones based on ecological security pattern: A case study in China. Natural Resources Research. https://doi. org/10.1007/s11053-018-9401-8.

Prasad, G., \& Ramesh, M. V. (2019). Spatio-temporal analysis of land use/land cover changes in an ecologically fragile area-Alappuzha District, Southern Kerala, India. Natural
Resources Research. https://doi.org/10.1007/s11053-018-9419$\mathrm{y}$.

Riccioli, F., Gabbrielli, E., Casini, L., Marone, E., El Asmar, J. P., \& Fratini, R. (2019). Geographical analysis of agro-environmental measures for reduction of chemical inputs in Tuscany. Natural Resources Research. https://doi.org/10.1007/s11053018-9398-z.

Sacchelli, S., \& Bernetti, I. (2019). Integrated management of forest ecosystem services: An optimization model based on multi-objective analysis and metaheuristic approach. Natural Resources Research. https://doi.org/10.1007/s11053-018-94134.

Smith, H. F., \& Sullivan, C. A. (2014). Ecosystem services within agricultural landscapes-Farmers' perceptions. Ecological Economics, 98, 72-80.

Statuto, D., Cillis, G., \& Picuno, P. (2019a). GIS-based analysis of temporal evolution of rural landscape: A case study in Southern Italy. Natural Resources Research. https://doi.org/ 10.1007/s11053-018-9402-7.

Statuto, D., Frederiksen, P., \& Picuno, P. (2019b). Valorization of agricultural by-products within the "energyscapes": Renewable energy as driving force in modeling rural landscape. Natural Resources Research. https://doi.org/10.1007/s11053018-9408-1.

Swinton, S. M., Lupi, F., Robertson, G. P., \& Hamilton, S. K. (2007). Ecosystem services and agriculture: Cultivating agricultural ecosystems for diverse benefits. Ecological Economics, 64(2), 245-252.

United Nations. (2015). Transforming our world: The 2030 agenda for sustainable development. New York, NY: Division for Sustainable Development Goals.

Vastola, A., Zdruli, P., D'Amico, M., Pappalardo, G., Viccaro, M., Di Napoli, F., et al. (2017). A comparative multidimensional evaluation of conservation agriculture systems: A case study from a Mediterranean area of Southern Italy. Land Use Policy, 68, 326-333.

Viccaro, M., Cozzi, M., Rocchi, B., \& Romano, S. (2019). Conservation agriculture to promote inland biofuel production in Italy: An economic assessment of rapeseed straight vegetable oil as a self-supply agricultural biofuel. Journal of Cleaner Production, 217, 153-161.

WCED. (1987). Our common future. Oxford: World Commission on Environment and Development, Oxford University Press. 